\title{
Identifying typical hourly DHW energy use profiles in a hotel in Norway by using statistical methods
}

\author{
Dmytro Ivanko ${ }^{* 1}$, Natasa Nord ${ }^{1}$, Åse Lekang Sørensen ${ }^{2}$, Thale Sofie Wester Plesser ${ }^{2}$, Harald Taxt Walnum², \\ and Igor Sartori ${ }^{2}$ \\ ${ }^{1}$ Department of Energy and Process Technology, Norwegian University of Science and Technology (NTNU), \\ Kolbjørn Hejes vei 1 B, Trondheim 7491, Norway \\ ${ }^{2}$ SINTEF, Department of Building and Infrastructure, P.O. Box 124 Blindern, 0314 Oslo, Norway
}

\begin{abstract}
The aim of this research is to improve the existing approaches of domestic hot water (DHW) energy use analysis in buildings. A comprehensive statistical analysis of hourly DHW energy use for a hotel in Oslo, Norway, was performed. To recognize the trend of DHW energy use over several years, Centered Moving Average method was applied. To increase the accuracy of DHW energy use analysis, it was proposed to identify the months and days of the week with similar characteristics of DHW energy use and build unified profiles for them. For this purpose, the approaches based on the student's t-tests and Fisher's test was proposed. The analysis allowed us to detect two seasons of DHW energy use. In addition, it was revealed that behavior of DHW energy use on Mondays significantly different from other working days. To recognize the timing of peak and average and low DHW energy use, method of statistical grouping of the hourly energy use was utilized. The typical profiles of DHW energy in the hotel were obtained. The profiles proposed in the present article more reliably reflect the regimes of DHW energy use in the hotel and take into account factors that have influence on DHW use.
\end{abstract}

\section{INTRODUCTION}

According to the European Commission, buildings are responsible for approximately $40 \%$ of energy use and $36 \%$ of $\mathrm{CO}_{2}$ emissions in the EU [1]. Energy efficiency saves money for buildings owners, reduces reliance on oil and gas and help protect the environment [2]. Through the Energy Performance of Buildings Directive (EPBD) an ambitious goal is set - to achieve very high energy performance in buildings, nearly zero-energy buildings, by 2020-2035 [3]. In order to achieve this goal, heating, cooling, and ventilation systems in buildings should be designed and operated to attain low energy use [4].

Traditionally, in countries with cold climate, energy used to heat domestic hot water (DHW) is much smaller than the energy use required for heating the building. For this reason, during the last decades, DHW energy use has had little focus in Norway and other countries [5]. Nowadays, with the introduction of energy efficient building technologies, the situation is changing. In energy efficient buildings, the energy use for heating is significantly reduced [6]. In meantime, the DHW energy use remains on the same level. Therefore, for future prospects in achieving energy efficiency in buildings reducing DHW energy use is an important task. Additionally, global warming potential (GWP) and primary energy demand (PED) for a range of DHW systems has high carbon footprint [6].

The share of DHW tap system in the total energy use is approximately $25-35 \%$ [7] and varying from country to country and one type of building to another [5]. For instance, the average individual DHW use in Norway reaches $40 \mathrm{~L} /$ person/day [8], while in Denmark the average is at $20 \mathrm{~L} /$ person/day.

The study of Bøhm [7] shows that the efficiency of domestic hot water systems should be improved. Heat losses from the hot water tank and the circulation system in single-family houses, semi-detached houses, blocks of flats, schools and institutions are found to be very high, and equals approximately to $65 \%$ of DHW energy use.

For the sake of simplification, many methodologies propose to consider DHW energy use as a constant value [9]. Practical experience shows that the commonly used standards are based on assumptions of DHW energy use in the buildings, which do not correspond to the real state of the art [10]. These assumptions and simplifications could lead to oversizing of the components of DHW systems and additional financial and energy losses [11].

DHW energy use profiles are the primary instrument for understanding the process of DHW energy use in the buildings [12]. Analysis of DHW energy use profiles shows the changes in energy use in different time intervals [13]. The profiles of DHW energy use allow us to determine the hours of peak energy loads and other energy load characteristics of a building. The DHW profiles is the basis for achieving energy saving and better building operation, as well as the best strategies for designing DHW systems in new buildings. Traditionally, the analysis of DHW energy use is performed based on socalled "typical" profile. This type of profile is viewed as a profile that shows how the energy for DHW is used most of the time. The identification of the time intervals when peak energy use occurs during the day is one of the key information available by analysis of the "typical" profiles.

\footnotetext{
* Corresponding author: dmytro.ivanko@ntnu.no
} 
Increasing the efficiency of DHW systems in buildings requires the implementation of effective demand-side management and energy conservation measures [14], as well as improvement of legislation and standards. Practical realization of smart management and energy saving measures in this field should be based on: 1) reliable knowledge about actual profiles [15] of DHW energy use in different types of buildings, 2) parameters that have a significant impact on DHW energy use, and 3) further analysis and processing of this information by statistical approaches. However, the knowledge about DHW energy use in Norwegian buildings currently remains at a relatively low level.

Statistical analysis is an effective tool for gaining indepth knowledge about DHW energy use and other parameters of buildings performance [16]. The primary issues, which should be solved for deeper understanding of DHW energy use by means of statistical approaches, are: 1) collection and pre-processing of data, 2) analysis of DHW energy use profiles, 3) identifying variables that have a significant impact on DHW energy use 4) modelling of DHW energy use.

Scientific works on DHW energy use patterns mostly focus on, residential buildings. Non-residential buildings (hospitals, hostels, schools etc.) are less studied [5]. Nevertheless, Michopoulos, Ziogou [17] estimated that $\mathrm{CO}_{2}$ emissions for hot-water use in the hotels remains quite high (2.87-3.2 $\mathrm{kg}-\mathrm{CO}_{2} /$ (person-night)) and the problem of DHW energy use analysis in non-resident buildings are meaningful. A better understanding of the features of DHW energy use is a key factor in achieving energy savings in buildings.

The issue of DHW energy use analysis in buildings based on profiles is investigated by researchers in Norway and abroad [5]. However, due to differences in particular characteristic of each buildings, quality of available data, and calculation requirement, there is no a unique methodology of performing appropriate analysis.

Most of the present researches assume that the number of occupants, seasons, the day of the week and time of the day have significant influence on DHW energy use. Traditionally, the data are divided into weekdays and weekends, while other options of separating data by other days of the week are usually not considered.

It should be noticed that due to cultural tractions, technical and weather conditions the factors having influence on DHW energy use can vary from country to country, from building to building and from family to family.

In this article we present methods of profiles development and time series analysis of DHW energy use data from a hotel in Oslo, Norway. The data comprises five years of hourly measurements of energy use for DHW production. The aim of this research is to improve the existing approaches of DHW energy use analysis in buildings. The research is part of the research project "Energy for domestic hot water in the Norwegian low emission society". The possible benefits from using more accurate energy profiles are explained.

\section{METHODOLOGY}

To detect the tendency of the changes in DHW energy use over several years, the Centered Moving Average method was used [18].

The common practice in DHW energy analysis, is to split of the profiles into different seasons, as well as into working and non-working days. As experience shows, the division of profiles into working days and non-working days is not always justified. In this study, we are not assuming, beforehand, that the profiles can be split in certain ways. Instead, we are comparing the DHW energy use profiles from different days of the week and assessing the similarities. The method uses student's t-test and Fisher's exact test. The tests can be used for samples with standard normal distribution and t-distribution. It allows us to determine the days of the week for with similar DHW energy use profile. The method is described in detail in Section 2.1.

In Section 2.2, a method for determining the duration and boundaries of time zones with peak, minimum, and average energy use during the day is described.

Seasonality has a significant impact on DHW energy use. However, which months should be included in each season and how many seasons should be taken into account when analyzing DHW energy use is not a completely solved task. In Section 2.3. a statistical method for identifying the number of seasons, as well as the months included in each season was described.

\subsection{Comparing similarity of DHW energy use profiles in different days of the week}

To determine the days of the week with similar characteristics of DHW energy use, a method based on test statistics was proposed. The similarity of two DHW energy use profiles is checked based on the student's t-test and Fisher's exact test. Appropriate tests can be used for samples with standard normal distribution and tdistribution.

By applying the t-test, it is possible to check if the mean values of DHW energy from two days of the week are equal or not. To achieve this, the DHW energy use within each day is considered as a statistical sample with 24 elements, which represents the number of hours in the day. The t-test statistical value can be calculated as follows:

$$
T_{\text {cal }}=\frac{\left\lceil\bar{E}_{\text {prof } 1}-\bar{E}_{\text {prof } 2}\right\rceil}{\sqrt{\frac{S_{\text {prof } 1}^{2}}{n_{\text {prof } 1}}+\frac{S_{\text {prof } 2}^{2}}{n_{\text {prof } 2}}}}
$$

where $\bar{E}_{\text {prof } 1}, \bar{E}_{\text {prof } 2}$ are mean values of DHW energy use in the first and second samples; $S_{\text {prof } 1}, S_{\text {prof } 2}$ are standard deviations of DHW energy use profiles in the first and second samples; $n_{\text {prof } 1}, n_{\text {prof } 2}$ the number of elements in the first and second samples. The formula for standard deviation for $i$-th day is:

$$
S_{\text {profi }}=\sqrt{\frac{\sum\left(E_{\text {profi.j }}-\bar{E}_{\text {profi }}\right)^{2}}{n_{\text {profi }}-1}}
$$


where $i$ is the number of the sample, $j$ is the number of element in the sample, $E_{\text {profi.j }}$ is DHW energy use in j-th element in $i$-th sample.

The obtained value of t-criteria $\left(T_{c a l}\right)$ is compared with the critical value $\left(T_{c r}\right) . T_{c r}$ can be found in reference literature for different sizes of samples and $k$ degrees of freedom. The comparison can lead to three possible situations:

- If $T_{\text {cal }} \leq T_{\text {cr }}\left(n_{\text {prof } 1}+n_{\text {prof } 2}-2, k=0.05\right)-$ the mean values of the first and second samples are similar;

- If $T_{\text {cal }} \geq T_{c r}\left(n_{\text {prof } 1}+n_{\text {prof } 2}-2, k=0.01\right)-$ the mean values of the first and second samples have a significant difference;

- If $T_{\text {cal }} \leq T_{c r}\left(n_{\text {prof } 1}+n_{\text {prof } 2}-2, k=0.01\right)$ and $T_{\text {cal }} \geq T_{\text {cr }}\left(n_{\text {prof } 1}+n_{\text {prof } 2}-2, k=0.05\right)-$ the mean values of the first and second samples can be considered as similar, however the final decision should be done based on the knowledge of researcher.

Meanwhile, Fisher's criterion allows us to estimate the similarity of two samples by variances:

$$
\mathrm{f}_{\text {cal }}=\frac{\max \left(\mathrm{S}_{\text {prof } 1}^{2}, \mathrm{~S}_{\text {prof } 2}^{2}\right)}{\min \left(\mathrm{S}_{\text {prof } 1}^{2}, \mathrm{~S}_{\text {prof } 2}^{2}\right)}
$$

The comparison of obtained by calculations Fisher criterion, $f_{c a l}$ with its critical value, $f_{c r}$ leads to the follow results:

- If $f_{\text {cal }} \leq f_{\text {cr }}\left(n_{\text {prof } 1}+n_{\text {prof } 2}-2, k=0.05\right)-$ the variances of the first and second samples are similar;

- If $f_{\text {cal }}>f_{c r}\left(n_{\text {prof } 1}+n_{\text {prof } 2}-2, k=0.05\right)-$ the variances of the first and second samples have significant difference.

The two profiles are considered to be similar if both student's t-test and Fisher's exact test show the same result. If at least one of two tests shows that the mean values or variances of profiles in first and second samples are not similar, we conclude that the profiles are dissimilar and should be analyzed separately.

Splitting DHW profiles by the days of the week should be made based on the large dataset, which represent DHW energy use during the year. Therefore, it was proposed to divide initial statistical data into separate weeks. Within each week, all combinations of daily DHW profiles should be compared among themselves by student's t-test and Fisher exact test. For instance, profiles for Monday and Thursday, Monday and Wednesday, Saturday and Sunday and so on should be compared. Afterwards, for all the combinations of days, the number of the week can be identified, when statistical tests show that profiles in considered pairs of days are similar. For further analysis, for each combinations of days the number of matches of DHW profiles in percentage can be found as:

$$
\mathrm{n}_{\mathrm{i} . \mathrm{j}}=\mathrm{N}_{\mathrm{i} . \mathrm{j}} \cdot 100 / \mathrm{N}_{\text {total }}
$$

where $n_{i . j}$ is number of matches in percentage, when DHW profiles on $i$-th and $j$-th days are similar, $N_{i . j}$ is number of weeks, when statistical tests shows that the $i$-th and $j$-th days are similar, $N_{\text {total }}$ is total number of weeks in statistical data sample of DHW energy use, $i$ is the day of the week of the first comparable profile (from 1 to 7 ), $j$ is the day of the week of the second comparable profile (from 1 to 7 ).
For better clarity, the results can be presented in the form of matrix of the matches as in Table 1 .

Table 1. The form of the matrix of matches

\begin{tabular}{|c|c|c|c|c|c|c|c|}
\hline & Mo. & Tu. & We. & Thu. & Fr. & Sa. & Su. \\
\hline Mo. & $n_{1.1}$ & $n_{1.2}$ & $n_{1.3}$ & $n_{1.4}$ & $n_{1.5}$ & $n_{1.6}$ & $n_{1.7}$ \\
\hline Tu. & $n_{2.1}$ & $n_{2.2}$ & $n_{2.3}$ & $n_{2.4}$ & $n_{2.5}$ & $n_{2.6}$ & $n_{2.7}$ \\
\hline We. & $n_{3.1}$ & $n_{3.2}$ & $n_{3.3}$ & $n_{3.4}$ & $n_{3.5}$ & $n_{3.6}$ & $n_{3.7}$ \\
\hline Th. & $n_{4.1}$ & $n_{4.2}$ & $n_{4.3}$ & $n_{4.4}$ & $n_{4.5}$ & $n_{4.6}$ & $n_{4.7}$ \\
\hline Fr. & $n_{5.1}$ & $n_{5.2}$ & $n_{5.3}$ & $n_{5.4}$ & $n_{5.5}$ & $n_{5.6}$ & $n_{5.7}$ \\
\hline Sa. & $n_{6.1}$ & $n_{6.2}$ & $n_{6.3}$ & $n_{6.4}$ & $n_{6.5}$ & $n_{6.6}$ & $n_{6.7}$ \\
\hline Su. & $n_{7.1}$ & $n_{7.2}$ & $n_{7.3}$ & $n_{7.7}$ & $n_{7.5}$ & $n_{7.6}$ & $n_{7.7}$ \\
\hline
\end{tabular}

Based on the matrix of matches the groups of the days of the week with similar profiles of DHW energy use could be identified. Namely, the days of the week, which have $n_{i . j} \geq 100$ - error, have similar characteristics of DHW energy use and should be placed in one group and analyzed together.

The value of error takes into account such factors as the accuracy of student's t-test $(5 \%)$, Fisher's exact test $(5 \%)$, and the percentage of days in the year when the building is not in operation such as holidays.

\subsection{Determining the time zones with peak, minimum and average energy use in daily profile of DHW energy use.}

It is known that DHW energy use changes during the day. In order to implement energy management in buildings, it is important to identify the typical duration and boundaries of time zones with peak load, minimum, and average energy use during the day.

To solve this issue, we are proposing to perform statistical grouping of the hourly capacity and consumer groups of the power system [19]. Initially this method has been used for identification of the tariff zones of electrical energy use in the power system. In this article, we have adapted the method for analysis of DHW energy use in buildings.

The method allows us to divide the hours of DHW energy use into several groups with statistically different mean values within each group. It is based on an iteration procedure and analysis of mean values of DHW energy use by applying student's t-test. In this case, DHW energy use profile was considered as a statistical sample $e$. The sample contains $\mathrm{N}=24$ elements (hours) with DHW energy use in these hours equal $e_{j}$ (where $e_{j}$ is DHW energy use in $j$-th hour, $j$ is the number of the element in the sample, $\mathrm{N}$ is number of elements in statistical sample e). The method includes the following steps:

1) The elements $e_{j}$ in the sample $e$ are sorted in the order of their increase. Such an arrangement of elements from smaller values of hourly DHW energy use to bigger values allows us to obtain the sorted sample $E$ with $\mathrm{N}$ elements $E_{i}$ (where $E_{i+1}>E_{i}, i$ is the number of element in sample $E$ ).

2) Based on the sample $E$, an iterative procedure of generating of two statistical subsamples $R_{1}$ and $R_{2}$ with variable number of elements is applied. On each step of 
iteration, sample $R_{1}$ contain M elements, while $R_{2}$ should have $\mathrm{M}+1$ elements. The elements in samples $R_{1}$ and $R_{2}$ were taken consistently from the initial sample $E$. With each iteration, the number of elements $M$ in these subsamples increases by one. The value of $\mathrm{M}$ varies from 1 to 23 .

On each step of these iterations the value of student's t-test for two subsamples $R_{1}$ and $R_{2}$ are calculated using Equation (1).

For instance:

iteration 1) $R_{1}=\left[E_{1}\right], R_{2}=\left[E_{1}, E_{2}\right], \mathrm{M}=1$, and $T_{\text {cal } 1}$; $T_{\text {cal2 }}$;

iteration 2) $R_{1}=\left[E_{1}, E_{2}\right], R_{1}=\left[E_{1}, E_{2}, E_{3}\right], \mathrm{M}=2$, and

$$
\text { iteration } 23) \quad R_{1}=\left[E_{1}, E_{2} \ldots E_{23}\right], \quad R_{1}=
$$
$\left[E_{1}, E_{2} \ldots E_{24}\right], \mathrm{M}=23$, and $T_{\text {cal } 23}$;

3) Based on the iteration procedure of the step 2, the series of t-criteria for all combinations of subsamples $R_{1}$ and $R_{2}, T_{\text {cal }}=\left[T_{\text {cal1 } 1}, T_{\text {cal2 }} \ldots T_{M}\right]$ are found.

If an ordered sample of hourly DHW energy use is monotonous, then the numerical values of elements in this sample increase evenly. In this case, the series of t-criteria obtained by iteration procedure will also be monotonous. This means that values of t-criteria obtained by Equation (1) will decrease monotonically with each next iteration $\left(T_{\text {cal1 }}>T_{\text {cal2 } \ldots>T_{M}}\right)$.

If the ordered sample of hourly DHW energy use is uneven, then a monotonic decrease of the calculated values of $\mathrm{t}$-criteria would be violated by periodic abrupt growth $\left(T_{\text {cali }}<T_{\text {cali+1 }}\right)$.

Thus, the identification of points of growth of the calculated values of t-criteria allows us to determine between which hours there is a noticeable statistical difference of DHW energy use. This assumption allows us to initially divide hours in the profile of DHW energy use into several groups. Each of these groups is the sample of data, where DHW energy use data varies monotonously.

Created in this way, neighboring groups of hourly DHW energy use can be checked in terms of the possibility for their further merge. For this purpose, the data samples of two neighboring groups are assessed by student's t-test (Equation (1)). As a result, the obtained by calculations value of t-criteria $\left(T_{c a l}\right)$ can be compared with critical value $\left(T_{c r}\right)$. This comparison can lead to three possible situations:

- If $T_{\text {cal }} \leq T_{c r}\left(n_{\text {group } 1}+n_{\text {group } 2}-2, k=0.05\right)-$ the mean values of two groups are similar and should be merged;

- If $T_{\text {cal }} \geq T_{\text {cr }}\left(n_{\text {group } 1}+n_{\text {group } 2}-2, k=0.01\right)-$ the mean values of two groups are different and they should be considered separately;

- If $\quad T_{\text {cal }} \leq T_{c r}\left(n_{\text {group } 1}+n_{\text {group } 2}-2, k=0.01\right)$ and $T_{\text {cal }} \geq T_{c r}\left(n_{\text {group } 1}+n_{\text {group } 2}-2, k=0.05\right)-$ the mean values of two groups can be considered as similar, however the final decision should be done based on the knowledge of researcher.

Step 3 is continued until the t-test shows that no groups can be merged together and that the total number of groups cannot be reduced.
4) Critical borders that separate DHW energy use profile into zones with peak, average and minimum energy use can be identified by the next formulas:

$$
\begin{aligned}
& \mathrm{E}_{\text {min }}=\overline{\mathrm{E}}_{\text {group } .1}+ \\
& +\mathrm{T}_{\text {cr.1 }}\left(\mathrm{M}_{\text {group } .1}+1-2,0.01\right) \sqrt{\frac{\mathrm{S}_{\text {group } .1}^{2}}{\mathrm{M}_{\text {group } .1}}} \\
& \mathrm{E}_{\text {max }}=\overline{\mathrm{E}}_{\text {group.K-1}}+ \\
& +\mathrm{T}_{\text {cr.K-1}}\left(\mathrm{M}_{\text {group } \mathrm{K}-1}+1-2,0.01\right) \sqrt{\frac{\mathrm{S}_{\text {group } \mathrm{K}-1}^{2}}{\mathrm{M}_{\text {group } \mathrm{K}-1}}}
\end{aligned}
$$

where $\bar{E}_{\text {group.1 }}, \bar{E}_{\text {group.K-1 }}$ are mean values of DHW energy use in the first group and next to the last group; $M_{\text {group.1 }}, M_{\text {group.K-1 }}$ are number of elements in the first group and next to the last group; $S_{\text {group.1 }}^{2}, S_{\text {group.K-1 }}^{2}$ are standard deviations in the first group and next to the last group; $T_{c r .1}, T_{c r . K-1}$ are critical values of $t$ criteria for the the first group and next to the last group. The hours in which DHW energy use is below $E_{\text {min }}$ should be considered as zone with the minimum DHW energy use. If DHW energy use is between $E_{\text {min }}$ and $E_{\text {max }}$ it can be assumed that in these hours DHW energy use is in a zone of average energy use. The hours with DHW energy use bigger then $E_{\max }$ lie within zone of maximum energy use.

\subsection{Determining the seasons of DHW energy use}

The method described in Section 2.2 can be applied in order to identify the groups of months with similar characteristics of DHW energy use. In this case, in contrast to the sample of 24 hours in daily profile, which was considered in Section 2.2, the initial sample contains 12 elements of monthly DHW energy use during the year. The basic principles and procedure of calculations in both hourly and monthly analysis is the same. As a result, the number of seasons of DHW energy use in the year and the months included in each season can be identified.

\section{HOTEL DESCRIPTION}

The characteristics of the hotel are typical for Scandinavian conditions and well aim to reflect the trends of DHW tap energy use in the similar types of buildings.

The hotel, located in Oslo, Norway, was built in 1938, and reconstructed in 2007. The total area of the building is $4939 \mathrm{~m}^{2}$, and consist of eight floors with 164 guest rooms. All guest have bathrooms with toilet facilities and shower. The rooms are cleaned daily. The maximum daily number of guests during the summer 2016 was 312 persons. Guests arrive between 15 p.m. to 12 midnight, and they check out before 12 noon. According to the hotel management, employees use hot water for cleaning the hotel, and guests use hot water for personal hygiene.

The hotel uses electricity to heat the water. The hot water is circulated to ensure fast delivery at taps. The circulation pump runs on fixed speed. In order to collect data of energy use in the building, electricity meters are installed, which allowed us to obtain hourly data of DHW 
energy use in the period 2013-2017. The meters measure electricity delivered to the DHW tanks, which mean that both DHW needs and heat losses in the DHW system is included in the presented DHW energy use. In addition, data about number of visitors were available from the hotel reservation system.

\section{RESULTS}

The results given in this section represent the practical application of proposed in the article methods and improvements, which were achieved. This section divided in several subsections that consider specific steps of investigation.

\subsection{The analysis of the trend of DHW energy use in the hotel}

Statistical data of energy use in the hotel substantiate that DHW tap systems have significant impact on energy use in the buildings. More specifically, in the hotel, DHW energy use constituted $19.5 \%$ of total energy use in 2016 and $23 \%$ in 2017 .

The annual trends in DHW energy use was analyzed by calculating the Centered Moving Average. The trend of DHW energy use in the hotel (Fig. 1) shows permanent growth in energy use from year to year. For instance, in 2017 DHW energy use increased by $11.6 \%$ compared to 2016.

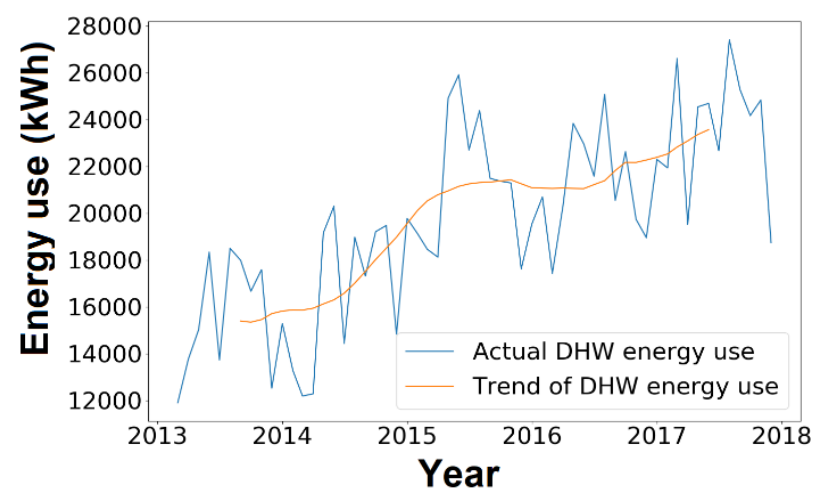

Fig. 1. Trend of DHW energy use in the hotel

A constant annual growth in energy use in the building may indicate a change in energy efficiency in DHW system, but could also reflect an increasing number of guests, changes in behavioral or administrative patterns related to the use of the building, or temperature changes.

DHW energy use per visitor for summer an early autumn in 2016 and 2017 years is shown in Fig. 2. June through September are the months with the highest energy use. The average energy use per visitor increased by $15.5 \%$ in 2017 compared with 2016. From Fig. 3 we can see that average monthly temperatures did not change significantly between 2016 and 2017. This indicates that the increase in DHW energy use caused by changes in the behavior of visitors or a decrease in the efficiency of the DHW system, rather than changes in the outdoor temperature.

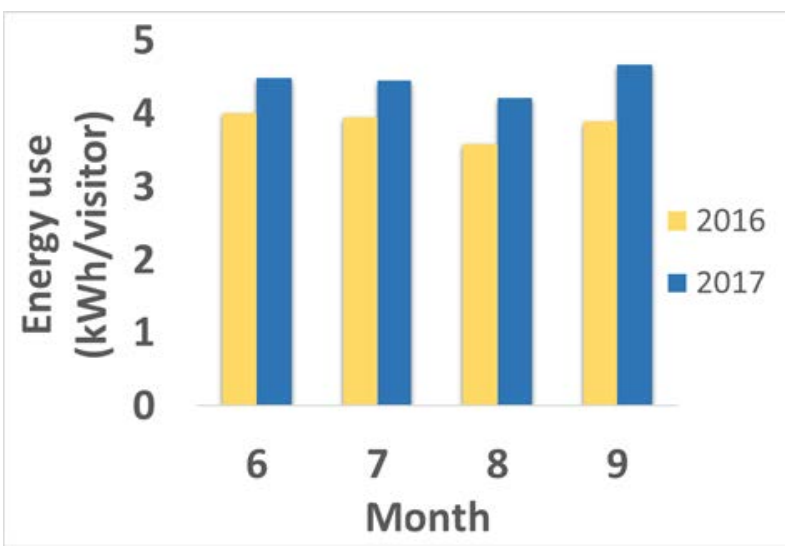

Fig. 2. DHW energy use per visitor in the warm season in 2016 and 2017

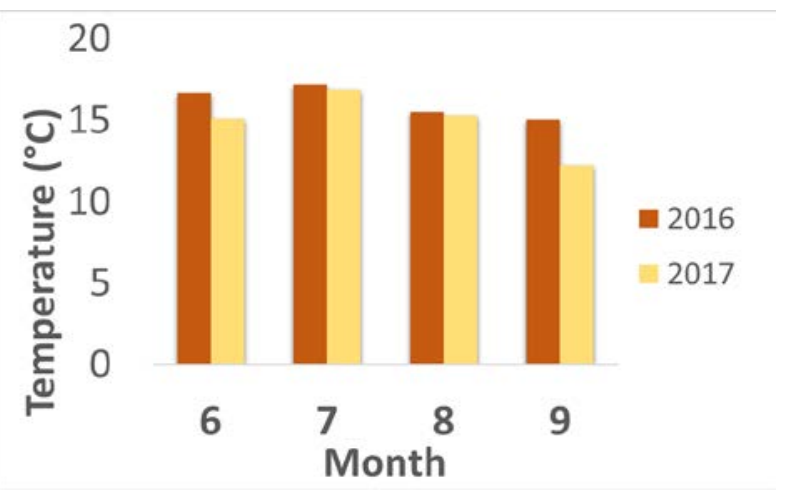

Fig. 3. Average monthly outdoor temperature in the warm season in 2016 and 2017

\subsection{DHW energy use profiles aggregated by similar days of the weeks and seasons}

The change of DHW energy between the months of June to September, within each year, is small, as shown in

Fig. 2. However, over a year the DHW energy use varies a lot more (Fig. 1). Therefore, it was necessary to identify the number of seasons of DHW energy use in the year, the months included in each season, and finally, develop separate profiles of DHW for each of these seasons.

In literature sources, it is suggested to consider separate DHW energy use profiles for working days and non-working days. However, this approach is simplified and may not give accurate results. Fig. 4 shows DHW energy use in representative week of 2016. From Fig. 4 we can see that DHW energy use on Mondays differs from that of the other working days. Taking the weekday into account allows us to obtain more accurate profiles of DHW energy use. 


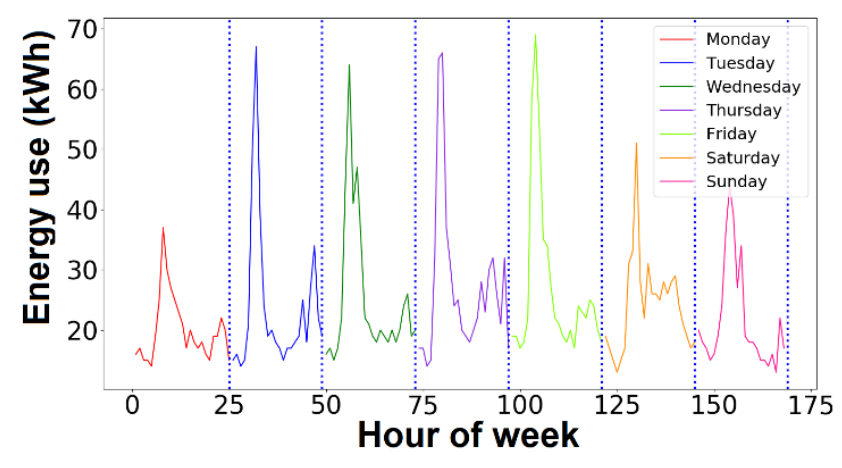

Fig. 4. DHW energy use during representative week of 2016

Seasons were identified in the average monthly DHW energy use data for last three years, using the method described in Section 2.3. Based on the t-criteria, the months of the year were divided into two groups with substantially different mean values of energy use within each group (Fig. 5). The groups represent the cold and warm seasons. The warm season includes the months May, June, July, August, September and October. January, February, March, April, November and December can be assigned to the cold season.

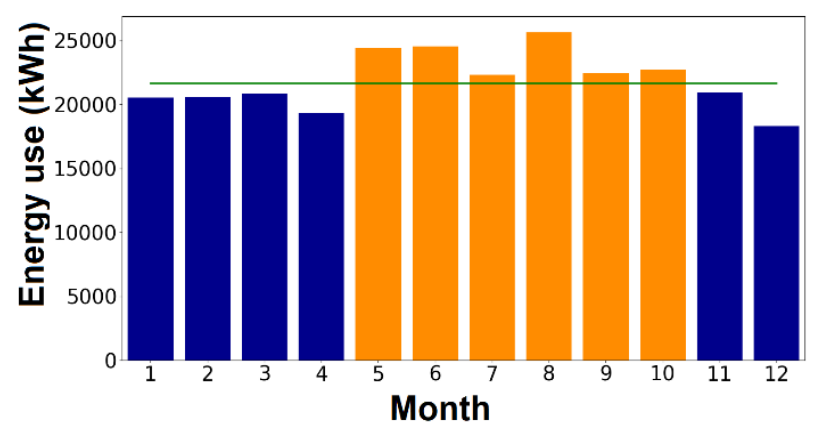

Fig. 5. Profiles of DHW energy use in the hotel divided by month and seasons

At the second step of the investigation, the days of the week were assessed for similarity. The available DHW use data was divided into separate weeks, in total 52 full weeks in the year. Within each week, all combinations of daily DHW profiles were systematically compared among themselves by student's t-test and Fisher exact test. The matrix of matching of daily profiles are shown in (Table 2).

In order to take in account the accuracy of student's ttest, Fisher's exact test, and the percentage of days in the year when the building is not in operation such as holidays, the value of error is accepted to be equal to $14 \%$. Therefore, the days of the week that have statistically similar profiles in more than $86 \%$ of considered weeks (Table 2) were identified. Based on this information next groups of the days were identified: 1) Monday, 2) Tuesday, Wednesday, Thursday, Friday, 3) Saturday, Sunday.
Table 2 Matrix of matching daily DHW energy use profiles

\begin{tabular}{|l|l|l|l|l|l|l|l|}
\hline & Mo. & Tu. & We. & Thu. & Fr. & Sa. & Su. \\
\hline Mo. & 100 & 42 & 30 & 30 & 34 & 22 & 20 \\
\hline Tu. & 42 & 100 & 86 & 84 & 80 & 64 & 64 \\
\hline We. & 30 & 86 & 100 & 92 & 86 & 78 & 70 \\
\hline Th. & 30 & 84 & 92 & 100 & 90 & 84 & 68 \\
\hline Fr. & 34 & 80 & 86 & 90 & 100 & 76 & 74 \\
\hline Sa. & 22 & 64 & 78 & 84 & 76 & 100 & 92 \\
\hline Sun. & 20 & 64 & 70 & 68 & 74 & 92 & 100 \\
\hline
\end{tabular}

Detailed DHW energy use profiles aggregated by similar days of the weeks and seasons are shown in Fig. 6. The profiles demonstrate the time zones with a peak (Emax), minimum (Emin) and average (Eaverage) energy use of DHW. These time zones were identified based on average daily DHW energy use by the method explained in section 2.2. The application of the method allowed us to determine the following borders of time zones:

1) if DHW energy use is more than $29 \mathrm{kWh}$ per hour, it corresponds to peak energy use;

2) if DHW energy use is less than $21 \mathrm{kWh}$ per hour, it corresponds to minimum energy use;

3) if DHW energy use is between $21 \mathrm{kWh}$ and 29.37 $\mathrm{kWh}$ per hour, it corresponds to average energy use.

The borders between time zones on Fig. 6 shown in the form of a straight lines.

Fig. 6 shows that profiles of DHW energy use in cold seasons and hot seasons are different by the shapes and maximum values of energy use. It can be seen from Fig. 6 that DHW energy use in the hot season is higher than in the cold season. This phenomenon can be explained by an increase in the number of guests in a summer period.

The analysis of profiles in Fig. 6 show than DHW energy use on Mondays is much smaller than in other days. For instance, the maximum energy use on Monday in a cold season was $40 \mathrm{kWh}$ and $55 \mathrm{kWh}$ in a hot season, meantime in other days it was equals $60 \mathrm{kWh}$ and $70 \mathrm{kWh}$ accordingly. A smaller number of visitors of the hotel on Mondays compared to other days of the week can explain these results.

The maximum energy use on working days usually occurs from 7 a.m. to 9 a.m. From 9 a.m. to 12 p.m. energy use tends to decrease, although it still remains quite high and corresponds to the pick energy use. The small spikes of energy use can also be observed in the hot season in the evening time from 21 p.m. to 23.00. Meantime, in a cold season, there is no peaks in energy use in the evening. Minimum energy use can be observed in midday and at night.

Peak energy use in weekends is shifted by one hour ahead compared to working days. The maximum energy use in weekends occurs from 9 a.m. to 11 a.m.

In general, the study shows that dividing DHW energy use profiles by season and days of the week is reasonable. The profiles obtained in this way are more informative and allow us retrieve additional information about DHW energy use in buildings. 


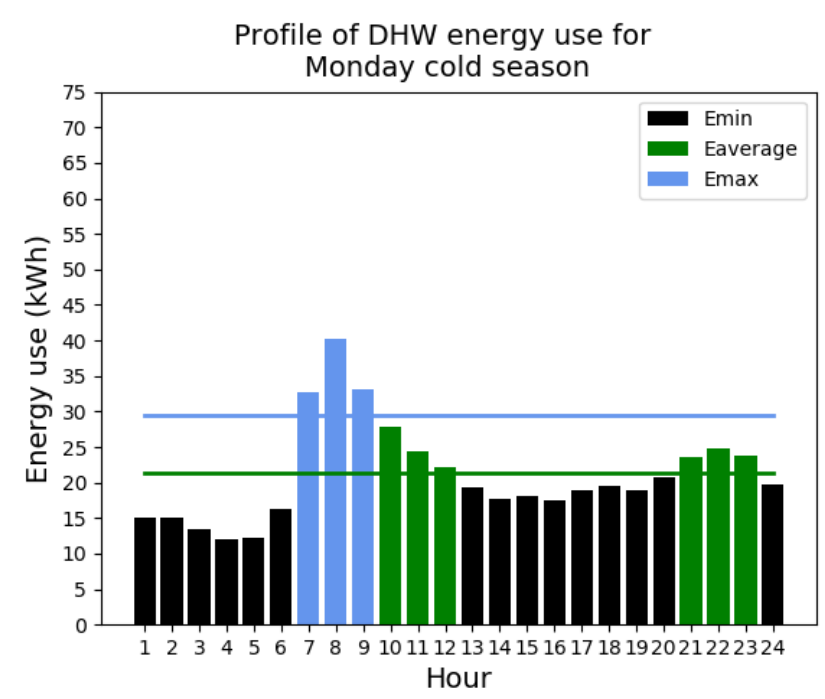

Profile of DHW energy use for

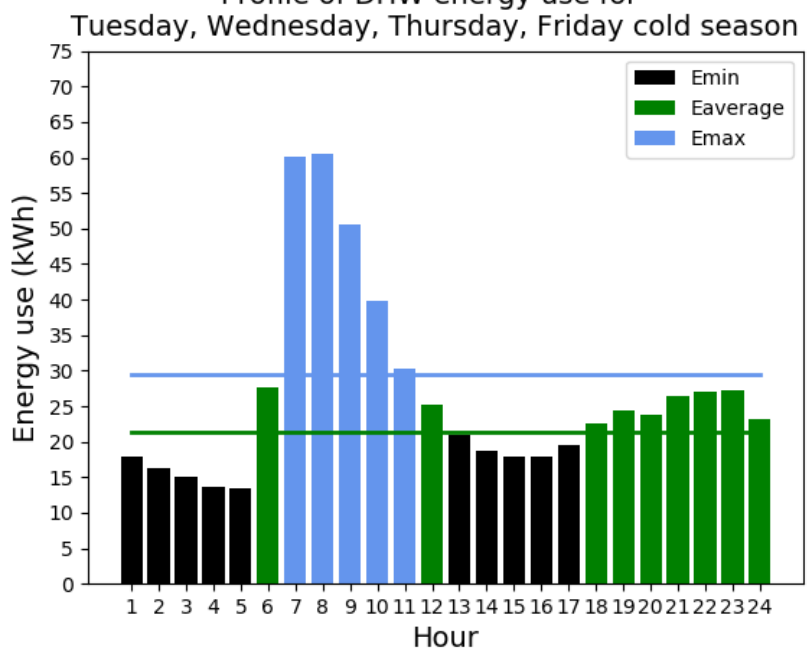

Profile of DHW energy use for Saturday, Sunday cold season

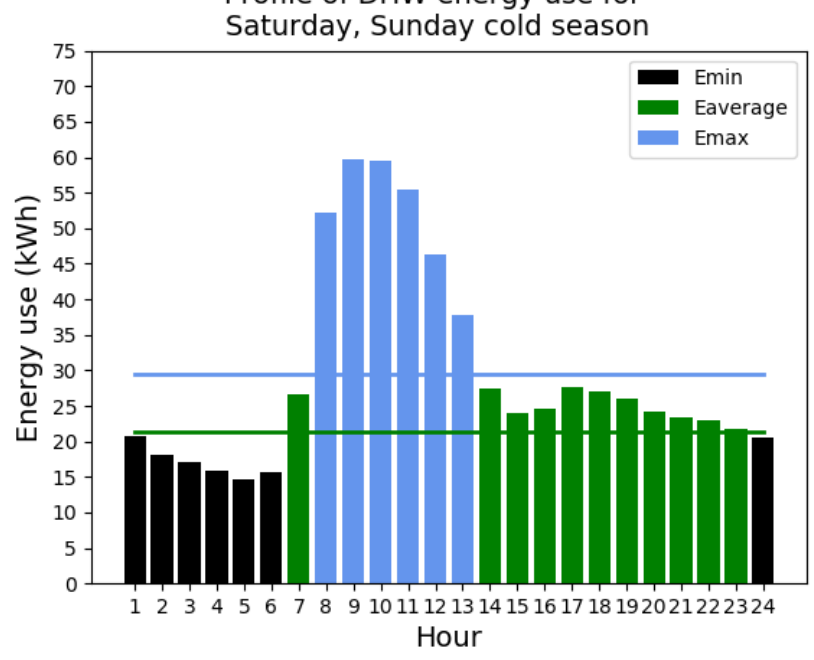

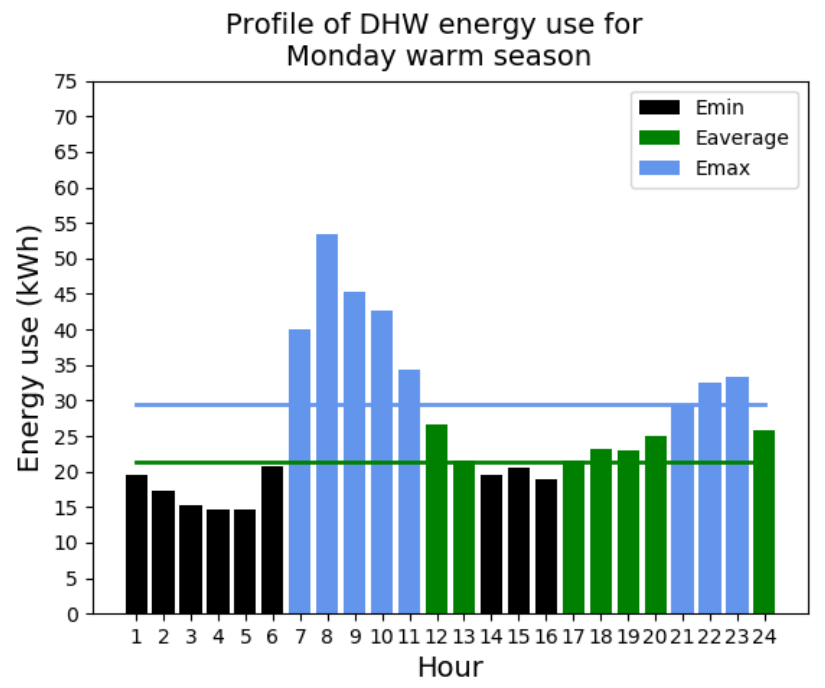

Profile of DHW energy use for

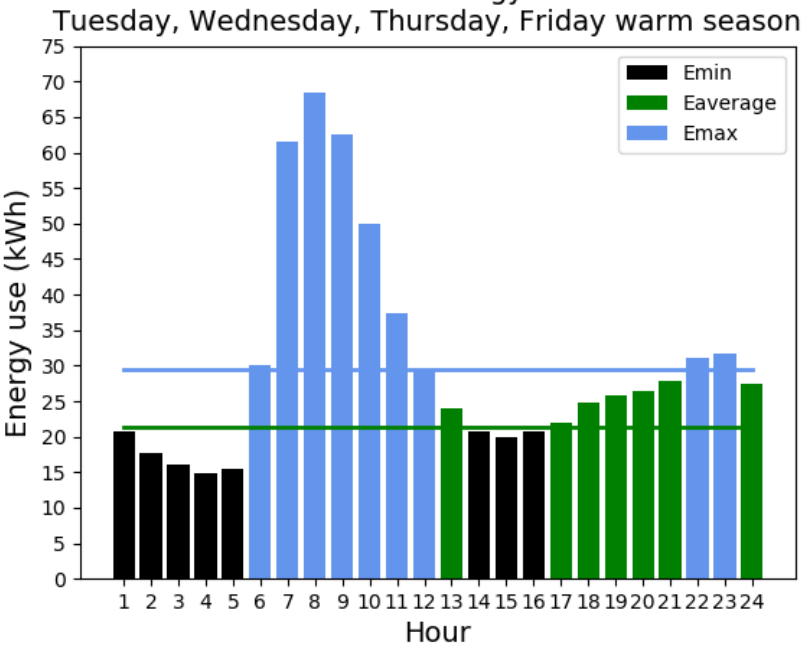

Profile of DHW energy use for

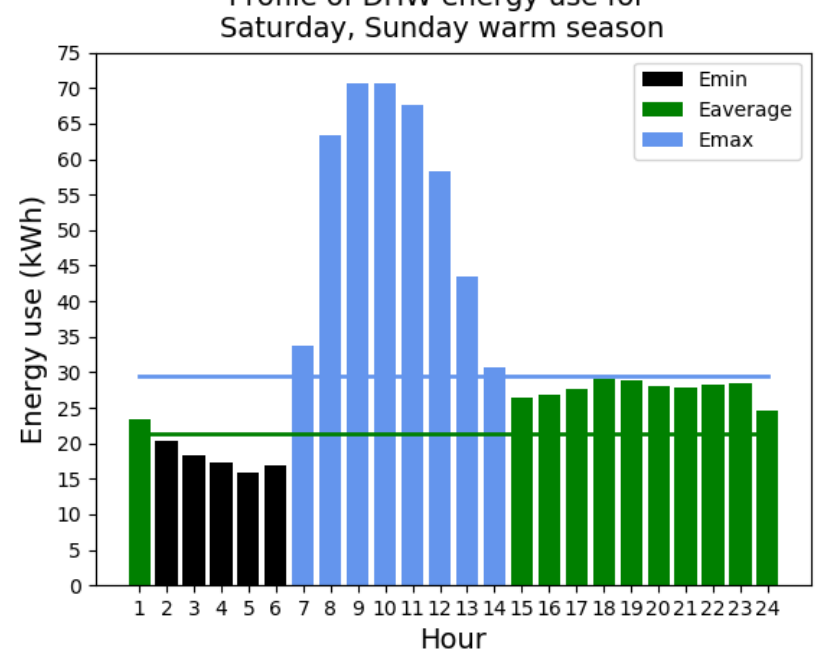

Fig. 6. Profiles of DHW energy use in the hotel divided by month and seasons

\section{CONCLUSIONS}

An important step in achieving energy efficiency in buildings is reducing the needs in DHW tap energy use. To solve this task we need reliable knowledge of DHW energy use in existing buildings. Analysis of DHW energy use profiles in different types of buildings is a powerful instrument for gaining appropriate knowledge.

The analysis described in this work show that the season of the year and the day of the week may influence DHW energy use. Therefore, in order to increase the accuracy of DHW energy use profiles, it is proposed to 
build unified profiles for months and days of the week with similar characteristics of DHW energy use.

A method, which identify the number of seasons of DHW energy use in the building and the months included in each season, is suggested. Based on student's t-criteria, the months of the year, for the hotel in this study, were divided into two groups: the cold season (January, February, March, April, November, December) and warm seasons (May, June, July, August, September, October).

Furthermore, a method for determining the time zones with peak, minimum and average energy use in daily profile of DHW energy use was applied.

For the analyzed hotel, the analysis of aggregated seasons and days of week, showed that DHW energy use in the hot season is higher than in the cold season. DHW energy use on Mondays is smaller than in other days. The maximum energy use in a working days occurs from 7 a.m. to 9 a.m., and from 9 a.m. to 12 p.m. remains high with a tendency to decrease. The results obtained in the article expand knowledge about methods of DHW energy use analysis in buildings.

\section{Acknowledgement}

This article has been written within the research project "Energy for domestic hot water in the Norwegian low emission society". The authors gratefully acknowledge the support from the Research Council of Norway (ENERGIX-programme), SINTEF Building and Infrastructure, Department of Energy and Process Engineering at NTNU, Drammen Eiendom, Omsorgsbygg, Boligbygg, OBOS, Olav Thon Gruppen, Armaturjonsson, Høiax, Geberit, Uponor and FM Mattsson.

\section{References}

[1] European Commission

https://ec.europa.eu/energy/en/topics/energyefficiency/buildings.

[2] European Commission wEE,

https:/ec.europa.eu/energy/en/topics/energy-efficiency.

[3] Max Jamieson OB, Yann Verstraeten, Joanne Arbon. EPBD Compliance Study - Final Report. Publications Office of the European Union. 2015:138.

[4] Abel E, Nilsson P-E, Ekberg L, Fahlén P, Jagemar L, Clark R, et al. Achieving the desired indoor climateenergy efficiency aspects of system design: Studentlitteratur, 2003.

[5] Fuentes E, Arce L, Salom J. A review of domestic hot water consumption profiles for application in systems and buildings energy performance analysis. Renewable and Sustainable Energy Reviews. 2018;81:1530-47.

[6] Sartori I, Hestnes AG. Energy use in the life cycle of conventional and low-energy buildings: A review article. Energy and buildings. 2007;39(3):249-57.

[7] Bøhm B. Production and distribution of domestic hot water in selected Danish apartment buildings and institutions. Analysis of consumption, energy efficiency and the significance for energy design requirements of buildings. Energy conversion and management. 2013;67:152-9.

[8] Ahmed K, Pylsy P, Kurnitski J. Monthly domestic hot water profiles for energy calculation in Finnish apartment buildings. Energy and Buildings. 2015;97:77-85.

[9] Levermore G, Chong W. Performance lines and energy signatures: review and analysis. Building Services Engineering Research and Technology. 1989;10(3):10514.

[10] Koiv T-A, Mikola A, Toode A. DHW design flow rates and consumption profiles in educational, office buildings and shopping centres. Smart Grid and Renewable Energy. 2013;4(03):287.

[11] Tindall J, Pendle J. Are we significantly oversizing domestic water systems? 2015.

[12] Yao R, Steemers K. A method of formulating energy load profile for domestic buildings in the UK. Energy and buildings. 2005;37(6):663-71.

[13] Kouveletsou M, Sakkas N, Garvin S, Batic M, Reccardo D, Sterling R. Simulating energy use and energy pricing in buildings: The case of electricity. Energy and Buildings. 2012;54:96-104.

[14] Djuric N, Novakovic V. Identifying important variables of energy use in low energy office building by using multivariate analysis. Energy and Buildings. 2012;45:91-8.

[15] Ma Z, Yan R, Nord N. A variation focused cluster analysis strategy to identify typical daily heating load profiles of higher education buildings. Energy. 2017; 134:90-102.

[16] Lomet A, Suard F, Chèze D. Statistical Modeling for Real Domestic Hot Water Consumption Forecasting. Energy Procedia. 2015;70:379-87.

[17] Michopoulos A, Ziogou I, Kerimis M, Zachariadis T. A study on hot-water production of hotels in Cyprus: Energy and environmental considerations. Energy and Buildings. 2017;150:1-12.

[18] Hamilton JD. Time series analysis: Princeton university press Princeton, NJ, 1994

[19] V.F. Nakhodov AIZ, Mohammad Al Sharari, D.O. Medintseva. Analysis of duration and border of existing tariff zones. Power engineering: economics, technology, ecology. 2016;2:97. 